\title{
Recall and clustering of verbal materials among normal and poor readers
}

\author{
BERNICE WONG \\ Faculty of Education, Simon Fraser University, Burnaby, British Columbia, Canada V5A IS6 \\ RODERICK WONG \\ Psychology Department, University of British Columbia, Vancouver, British Columbia, Canada V6T IW5
}

and

\author{
DENIS FOTH \\ Continuing Education, Simon Fraser University, Burnaby, British Columbia, Canada V5A IS6
}

The recall and clustering of verbal materials among normal and poor readers was investigated. The results indicated quantitative differences between the two groups of readers. More importantly, the results also indicated that normal readers were able to maximize extra given time to learn and organize materials for remembering. Additionally, they were able to generate their own mnemonic strategies in the absence of instructional cues. The results were interpreted in terms of the poor reader's unadaptiveness to the experimental task. Such unadaptiveness appears to be a function of production deficiency in mnemonic strategies.

The solution to the problem of reading disability among intellectually intact children has proved to be a significant challenge for psychologists and educators. For years reading problems were thought to involve inaccurate perception of letters, words, and visual memory problems (Bender, 1957; Cruickshank, 1972; Frostig, 1967; Kephart, 1960). However, recent research has cast doubts on this "perceptual deficit" hypothesis and pointed instead to deficits in memory processes (Allington, Gormley, \& Truex, 1976; Morrison, Giordani, \& Nagy, 1977; Vellutino, Steger, \& Kandel, 1972; Vellutino, Steger, Moyer, \& Harding, Note 1; Vellutino, Note 2).

Poor readers may have problems in organization of memory (Blank, 1968; Blank \& Bridger, 1966, 1967; Senf \& Freundl, 1971). More specifically, Blank has suggested that, compared to normal readers, poor readers are less able to conceptualize the demands of given tasks. Moreover, she suggests that they process input poorly and organize input inefficiently for subsequent recall or recognition. Senf and Freundl (1971) found that poor readers were highly deficient in recalling given items in two modality sets, visual and auditory. They suggested memory organization problems as one possible cause of the poor reader's performance. Clearly, we need to investigate whether poor readers have problems in memory organization. Specificaily, if it was the case that poor readers have problems in memory organi-

This research was supported by a grant from the President's Research Fund Committee at Simon Fraser University. We thank Lewis Varga for his assistance in computer programming for data analyses. Reprint requests should be addressed to Bernice Wong. zation, they would recall significantly fewer correct items as well as show significantly less clustering in items recalled than would normal readers.

The present experiment manipulated the effects of the presence or absence of cuing and conditions of timing on memory processes among normal and poor readers. It has been found that directly cuing subjects to use category headings to organize stimulus input increases the number of items subsequently recalled (Lange, 1973). Thus, comparing poor readers with and without direct cues to organize items for subsequent recall would enable us to assess the effects of cuing on recall with this group. The pertinence of such information lies in enabling us to pinpoint production deficiency rather than mediational deficiency as the cause of poor recall among poor readers (cf. Flavell, Beach, \& Chinsky, 1966).

In the usual free recall studies in verbal learning, subjects are timed in their viewing of the stimulus words. We have reason to believe that poor readers may function poorly under timed conditions (Blank, 1968; Dykman, Walls, Suzuki, Ackerman, \& Peters, 1970). In order to provide an opportunity for optimum performance among poor readers, we manipulated two levels of the timing variable, timed vs. self-paced stimulus viewing.

\section{METHOD}

\section{Subjects}

The subjects were 96 children attending Grades 4 and 5 in a suburban school district in Vancouver, British Columbia. Of these, 48 were learning-disabled children ( 35 boys and 13 girls) who ranged in age from 8 years 11 months to 11 years 
11 months, with a mean age of 10 years 1 month. They had been identified through formal psychological and educational assessments by the local school district personnel as having learning disabilities. More specifically, the learning-disabled subjects were reading 1-2 years below grade level on the oral reading section of the Durrell (1955) Analysis of Reading Difficulty Test. In addition, they had normal intelligence scores on the Slosson (1973) Intelligence Test (IQ 90-109). They had been randomly selected from learning assistance centers (LACs) with one restriction: A raw score of $10-11$ on the WISC subtest of Digit Span was required. The restriction was necessary because this study investigated organization of memory, and poor memory span among subjects would confound the results. According to the WISC manual, a raw score of 10-11 corresponds to the ages of our subjects (Wechsler, 1974). The learning-disabled children were receiving special tutorial assistance from the teachers in the LACs at their regular schools for about $1 \mathrm{~h}$ daily. However, they rejoined their classes for the rest of the day.

A control group of 48 normal children were randomly selected from elementary school classes attended by the learningdisabled subjects, matching the latter in age, sex, and raw score on the WISC subtest of Digit Span. The control subjects were tested on the oral reading section of the Durrell test to be reading at grade level or above. They showed average intelligence on the Slosson test (IQ 90-109) and had no record of academic or emotional problems.

\section{Materials}

The stimuli consisted of 16 words distributed evenly across four conceptual categories (human body parts, vehicles, clothing, and animals). The words were: arm, head, hand, neck, dog, cat, cow, deer, car, plane, meaning airplane, truck, bus, dress, suit, shirt, and pants). The stimuli were randomly selected from one of four sets used by Vaughan (1968). Each word was printed in black on $12.7 \times 7.6 \mathrm{~cm}$ index cards. In addition, each of the four conceptual headings (e.g., clothing) was printed on larger white cards measuring $15.2 \times 10.1 \mathrm{~cm}$.

The practice set of stimuli consisted of eight words printed on white index cards the same size as those containing the 16 stimulus words for the experiment proper. These eight words were evenly distributed across four conceptual categories of food, animals, furniture, and clothing. They consisted of stove, camel, necktie, candycane, bench, pretzels, goats, and apron.

\section{Procedure}

The experimental task was administered to subjects individually in assigned rooms in the schools. Each subject sat at the table opposite the experimenter. All subjects were given practice with the set of eight words to insure that they understood the nature of the recall task and that subjects in each instructional condition understood the instructions they were to follow during the task. The experiment began with the experimenter presenting the subject the 16 words in a random order. The subject read aloud each word and the experimenter corrected any misreading. Each card was put on the table after the subject had read it. All subjects were given an interval of $20 \mathrm{sec}$ after viewing before recalling the words. Moreover, they were allowed $72 \mathrm{sec}$ in which to recall all the instances. The procedural differences in cued and no-cue conditions and the timed vs. untimed conditions are summarized below.

Cued condition. At the start of the viewing period, the experimenter named each category and asked the subject to point to and name the category instances one category at a time. Immediately after the subject labeled the stimulus words by category, he was asked to learn conceptually related items together and was told that he would have to remember them in that way when it was time for recall. Following such instructions, four cards, on each of which was printed a category heading, were presented and laid above the array of stimulus words. The experimenter named these four cards for the subject. The cards with category headings remained present throughout the stimulus-viewing period. During the recall period, the experimenter retrieved all stimulus words except the four cards with category headings. The subject was allowed $72 \mathrm{sec}$ to recall all the instances.

No-cue condition. The naming procedure for the practice set and the experimental stimulus words was identical to that in the cued condition. The subject was then told to learn all the words for subsequent recall without being instructed on how to learn them. During the stimulus-viewing and recall periods, no cards bearing category headings were presented.

Timed condition. All subjects were given $90 \mathrm{sec}$ for viewing the stimulus words. When the time limit expired, the experimenter removed all stimulus words. Recall commenced after a delay of $20 \mathrm{sec}$.

Untimed condition. Subjects were allowed to self-pace their viewing of stimulus words. When they considered themselves ready for the recall, they informed the experimenter, who then removed the stimulus words. After a 20 -sec delay, recall commenced. The time each subject took during stimulus viewing was recorded. However, a maximum of $180 \mathrm{sec}$ was set as the time limit.

\section{Response Measures}

Recall and cluster performances of subjects were measured. The measure of clustering in recall was obtained by using the item clustering index (ICI). The ICI (Robinson, 1966) is computed by the formula $I C I=r / c(W c-1)$, where $r$ equals the number of category pairs occurring contiguously in recall, $c$ is the number of categories present in recall, and Wc is the number of items per category in the stimulus array.

In addition, three measures were used to record subjects' study behaviors during the stimulus-viewing period. The study behaviors recorded were: (1) self-testing-looking away from the picture array and trying to reproduce the items from memory (as judged by clearly discernible lip movements); (2) moving pictures-moving them in a conceptual grouping; and (3) verbalizing aloud or whispering with clearly discernible lip movements. Two independent raters made judgments on the occurrence of the study behaviors for every 15 -sec interval during the stimulusviewing period (cf. Moely, Olson, Halwes, \& Flavell, 1969).

Reliabilities of each behavioral category were obtained by comparing the ratings of the two raters on 24 subjects. The reliabilities of the raters were $.73, .89$, and .81 , respectively, for the three behaviors rated.

\section{RESULTS}

\section{Recall Performance}

A 2 by 2 by 2 (groups by instructions by timing) analysis of variance yielded significant main effects of groups and instructions. Normal readers recalled significantly more correct items than poor readers $[\mathrm{F}(1,88)=$ $8.69, \mathrm{p}<.01]$. Moreover, subjects in the cued condition recalled significantly more correct items than subjects in the no-cue condition of instruction $[F(1,88)=19.56$, $\mathrm{p}<.001]$. Table 1 presents the means and standard deviations in recall and clustering among the normal and poor readers.

Post hoc comparisons with the Tukey h.s.d. test of the eight means in recall performance indicated several important findings significant at the .05 level. (1) Poor readers in the no-cue/timed and no-cue/untimed conditions performed significantly poorer than subjects in all other treatment groups. (2) Poor readers in the cued/ timed condition performed poorer than normal readers 
Table 1

Means and Standard Deviations in Recall and Clustering Performance Among Normal and Poor Readers

\begin{tabular}{|c|c|c|c|c|c|c|c|c|c|}
\hline & \multirow[b]{3}{*}{ Groups } & \multicolumn{8}{|c|}{ Conditions } \\
\hline & & \multicolumn{2}{|c|}{ Cued/Timed } & \multicolumn{2}{|c|}{ Cued/Untimed } & \multicolumn{2}{|c|}{ No Cue/Timed } & \multicolumn{2}{|c|}{ No Cue/Untimed } \\
\hline & & Mean & SD & Mean & SD & Mean & SD & Mean & $\mathrm{SD}$ \\
\hline Recall & Normal Readers & 14.58 & 1.24 & 15.08 & 1.56 & 13.96 & 2.11 & 13.61 & 2.13 \\
\hline Performance & Poor Readers & 13.56 & 1.98 & 13.70 & 1.90 & 12.00 & 2.80 & 12.00 & 2.48 \\
\hline Clustering & Normal Readers & .74 & .07 & .77 & .05 & .61 & .29 & .61 & .32 \\
\hline Performance & Poor Readers & .72 & .23 & .60 & .19 & .41 & .22 & .66 & .26 \\
\hline
\end{tabular}

in both cued/timed and cued/untimed conditions. The same applied to poor readers in the cued/untimed condition. (3) Normal readers in the no-cue/untimed condition recalled significantly fewer correct items than their counterparts in the cued/timed and cued/untimed conditions. (4) Normal readers in the no-cue/timed condition recalled significantly fewer correct items than their counterparts in the cued/untimed condition.

\section{Clustering Performance}

The clustering data were subjected to a 2 by 2 by 2 (groups by instructions by timing) analysis of variance. The results indicated that the main effects of groups and instructions were significant. Normal readers clustered items in recall significantly more than poor readers $[F(1,88)=4.25, p<.05]$. Moreover, subjects in the cued condition clustered items in recall significantly more than subjects in the no-cue condition $[F(1,88)=$ $10.38, \mathrm{p}<.01]$. None of the interactions reached significance. However, the triple interaction approached significance $[F(1,88)=3.09, p=.082]$.

Post hoc comparisons of the eight means in clustering performance indicated two significant findings. In the cued/untimed condition, normal readers showed significantly more clustering of items than poor readers. Similarly, in the no-cue/timed condition, normal readers also showed significantly more clustering (Tukey h.s.d. test, $\mathrm{p}<.05$ ).

\section{Study Behaviors}

Only the behavioral category of verbalization significantly differentiated the two groups of normal and poor readers $[t(94)=1.78, p<.05]$. Normal readers verbalized the names of the stimuli significantly more often than the poor readers.

\section{DISCUSSION}

In general, the results indicated quantitative differences in recall and clustering between normal and poor readers. The significance and interest of the present experiment concern the following issues. Normal readers in the cued/untimed condition recalled and clustered significantly more than poor readers given the same treatment. This suggests that normal readers were able to exploit the extra time given to learn and organize items for subsequent recall. Similarly, normal readers in the no-cue/timed condition recalled and clustered significantly more than poor readers given the same treatment. This suggests that normal readers were able to generate spontaneously mnemonic cues from the stimuli to aid their learning and organization of items for subsequent recall. In striking contrast, poor readers did not actively use the extra given time to learn and organize the stimuli for subsequent recall. Nor did they actively generate mnemonic cues to organize and to aid learning of the stimuli. Because the times used had high interitem associations (cf. Lange, 1973), the poor readers' lack of action in generating their own mnemonic cues emphasizes their unadaptiveness to the experimental situation.

The unadaptiveness of the poor readers may be explained in two ways: (1) that they had problems in conceptualizing the demands of the given task (cf. Blank, 1968) or (2) that they were inactive learners (i.e., they showed a performance deficit rather than an ability deficit) (cf. Torgesen, 1977). Although the possibility of conceptualizing problems exists among poor readers, the present data appear to support the alternative explanation of unadaptiveness among poor readers. That the poor readers in this experiment were inactive learners or showing a performance deficit is supported by the finding that poor readers verbally rehearsed the items significantly less often than did normal readers. Because verbal rehearsal has been shown to increase recall (Keeney, Cannizzo, \& Flavell, 1967), it appears reasonable to interpret the poor reader's performance deficit in recall as a function of insufficient verbal rehearsal. Additional evidence which supports a performance deficit interpretation of the results rather than the interpretation of a conceptualization deficit appears in the following. In the cued/timed condition, despite lower recall, poor readers showed the same degree of clustering or organization of memory as normal readers. Moreover, when normal and poor readers were denied cues but given extra time, as in the no-cue/untimed condition, they did not differ from one another in the organization of memory. This suggests that poor readers had neither a deficit in conceptualizing the demands of the task nor a deficit in the ability to organize items for remembering. Rather, they evidenced a performance deficit in recall.

It appears, then, that the poor readers were inactive learners who failed to produce the appropriate strategies in the given experimental task. The strategy needed to increase recall was verbal rehearsal, and the strategy needed to increase clustering in the absence of instructional cues was the devising of a mnemonic system of one's own. Because they failed to produce situationally relevant strategies for reasons other than the sheer lack of ability or skill to enact it properly, the poor readers may be construed as demonstrating a "production deficiency" (Flavell, 1970, 1977). Although production deficiency accounts largely for their unadaptiveness to the experimental task, it does not explain the poor reader's ineffective use of the extra time. The absence of significant differences due to the time variable among poor readers may reflect the clinical observation that these children require very structured task settings for optimal performance (Hallahan \& Kauffman, 1976). Thus, the extra time given availed little for them when they were not given any structure on how to use the time allotment. 


\section{REFERENCE NOTES}

1. Vellutino, F. R., Steger. B. M., Moyer, S. C., Harding, C. J., \& Miles, J. A. Has the perceptual deficit hypothesis led us astray? An examination of current conceptualizations in the assessment and treatment of exceptional children. Paper presented at the Annual International Convention of the Council for Exceptional Children, New York City, April 1974.

2. Vellutino, F. R. Psychological factors in reading disability. Paper presented at annual convention of AERA, Chicago, Illinois, April 1974.

\section{REFERENCES}

Allington, R. L., Gormley, K., \& Truex, S. Poor and normal readers' achievement on visual tasks involving high frequency, low discriminability words. Journal of Learning Disabilities, 1976, 9. 34-38.

BENDER, L. Specific reading disability as a maturational lag. Bulletin of the Orton Society, 1957, 7, 9-18.

BlaNk, M. Cognitive processes in auditory discrimination in normal and retarded readers. Child Development, 1968, 39. 1091-1101.

Blank, M., \& BRIDGer, W. H. Deficiencies in verbal labelling in retarded readers. American Journal of Orthopsychiatry, 1966, 36, 840-847.

BlaNk, M., \& Bridger, W. H. Perceptual abilities and conceptual deficiencies in retarded readers. In J. Zubin (Ed.), Psychopathology of mental development. New York: Grune \& Stratton, 1967. Pp. 401-412.

Cruickshank, W. M. Some issues facing the tield of learning disability. Journal of Learning Disabilities, 1972. 5. 380-383.

Durrell, D. D. The Durrell analysis of reading difficulty (Rev. ed.). New York: Harcourt, Brace \& World, 1955.

Dykman, R. A.. Walls, R. C., Suzuki, T., Ackerman, P., \& Peters, J. E. Children with learning disabilities: Conditioning, differentiation, and the effect of distraction. American Journal of Orthopsychiatry, 1970, 40, 766-782.

Flavell, J. H. Developmental studies of mediated memory. In H. W. Reese \& L. P. Lipsitt (Eds.), Advances in child development and behavior (Vol. 5). New York: Academic Press, 1970. Pp. 181-211.

Flavell, J. H. Memory. In J. H. Flavell (Ed.), Cognitive development. Englewood: Prentice-Hall, 1977. Pp. 183-218.

Flavell, J. H., Beach, D. R., \& Chinsky, J. M. Spontaneous verbal rehearsal in a memory task as a function of age. Child Development, 1966, 37, 282-299.
Frostig, M. Education of children with learning disabilities. In E. C. Frierson \& W. B. Barbe (Eds.), Educating children with learning disabilities. New York: AppletonCentury-Crofts, 1967.

Hallahan, D. P., \& Kauffman, J. M. Introduction to learning disabilities, a psychobehavioral approach. Englewood-Cliffs: Prentice-Hall, 1976. Pp. 150-178.

Keeney, T. J., Cannizzo, S. R., \& Flavell, J. H. Spontaneous and induced verbal rehearsal in a recall task. Child Development, 1967, 38, 953-966.

KEPHART, N. C. The slow learner in the classroom. Columbus: Merrill, 1960.

LANGE, G. The development of conceptual and rote recall skills among school age children. Journal of Experimental Child Psychology, 1973, 15, 394-406.

Moely, B. E., Olson, F. A., Halwes, T. G., \& Flavell, J. H. Production deficiency in young children's clustered recall. Developmental Psychology, 1969, 1, 26-34.

Morrison, F. J., GIORDANI, B., \& NAGY, J. Reading disability: An information-processing analysis. Science, 1977, 196, 77.79.

Robinson, J. A. Category clustering in free recall. Journal of Psychology, 1966, 62, 279-285.

Senf, G. M., \& Freundi, P. D. Memory and attention factors in specific learning disabilities. Journal of Learning Disabilities, 1971, 4, 94-106.

SLosson, R. L. The Slosson intelligence test for children and adults. New York: Slosson Educational Publications, 1973.

Torgesen, J. K. The role of nonspecific factors in the task performance of learning disabled children: A theoretical assessment. Journal of Learning Disabilities, 1977, 10. 27-34.

VAUGHAN, M. E. Clustering, age and incidental learning. Journal of Experimental Child Psychology, 1968, 6. 323-334

Vellutino, R. F., Steger, J. A., \& Kandel, G. Reading disability: An investigation of the perceptual deficit hypothesis. Cortex, 1972, 8, 106-118.

WECHSLER, D. The Wechsler intelligence scale for children-Revised. New York: Psychological Corporation, 1974. 